\title{
THE INFLUENCE OF PERFORMANCE APPRAISAL ON THE PSYCHOLOGICAL CONTRACT OF THE INPATRIATE MANAGER
}

\begin{abstract}
Author:
Jane F. Maley ${ }^{1}$
\end{abstract}

\section{Affiliation: \\ ${ }^{1}$ Macquarie Graduate School of Management, Macquarie University,} Australia

\section{Correspondence to:}

Jane F. Maley

e-mail:

jane.maley@mgsm.edu.au

\section{Postal address:}

2/1 Bayiew Street, Lavender Bay, NSW, Australia, 2060

\section{Keywords:}

inpatriate manager; performance management; health care; bottom line; psychological contract

\section{Dates:}

Received: 21 Nov. 2008 Accepted: 25 June 2009 Published: 17 Sept. 2009

How to cite this article: Maley, J.F. (2009). The influence of performance appraisal on the psychological contract of the inpatriate manager. $S A$ Journal of Human Resource Management/SA Tydskrif vir Menslikehulpbronbestuur, 7(1), Art. \#179, 10 pages. DOI: 10.4102/sajhrm.v7i1.179

\section{This article is available} at:

http://www.sajhrm.co.za

(C) 2009. The Authors. Licensee: OpenJournals Publishing. This work is licensed under the Creative Commons Attribution License.

\begin{abstract}
This article explores the extent, nature and limitations of performance appraisals, and the subsequent influence that these issues may have on the psychological contract of inpatriate managers in a sector of the health care industry in Australia. 18 in-depth interviews using a grounded theory methodology revealed that the process was significantly influenced by multinational organisations' emphasis on the bottom line and the inpatriate manager's relationship with his/ her supervisor. Furthermore, the findings suggest that the inpatriate manager's experience of his/ her performance appraisal frequently results in a perception of violation of his/her psychological contract with the organisation.
\end{abstract}

\section{INTRODUCTION}

Owing to the current dynamic business environment, international human resource practitioners are compelled to actively lead in improving multinational organisations' effectiveness as performancemanagement specialists. In order for practitioners to establish such performance-management systems, it is critical that job performance be clearly understood and that individual employees are given rewards and development opportunities on the basis of fair and accurate performance evaluation (Bae, 2006; Williams, 2002). In other words, major parts of a multinational organisation's global performancemanagement system must be clarified and well designed, so that the performance-management system will be able to function effectively throughout the entire international organisation. Evidence indicates that multinational organisations and their subsidiaries are an increasingly important part of the global business landscape (Harzing \& Noordhaven, 2005). This places an immense dependence on the subsidiary and, as a consequence, a strong reliance on the manager of the subsidiary, commonly called the inpatriate manager. These managers are usually isolated from their supervisors. They are responsible for the performance of the subsidiary and implement strategically critical tasks, such as the management of a number of staff, and carry responsibility for the achievement of the revenue and profitability targets of the subsidiary. The inpatriate manager must be able to manage these tasks within the objectives and guidelines handed down by the multinational organisation. The performance of the inpatriate manager is, therefore, critical to the success of the multinational organisation. Nonetheless, little research has focused on this critical international employee in relation to either performance appraisal or a set of reciprocal expectations between the employee and the employer, which has been termed the psychological contract.

Performance appraisals are an integral part of the wider performance-management system and are extensively used to evaluate international employees (Gratton, 2000; Milliman, Nason, Zhu \& De Cieri, 2002). Despite their importance and prevalent use, the implementation of performance appraisals is frequently defective in a number of ways. These limitations include erroneous judgements about performance, unproductive feedback, invalid performance criteria and a lack of transparency about the purpose of the system (Maley \& Kramar, 2007; Whitford \& Coetsee, 2006). At the same time, a performance appraisal cannot be an exclusive process, and the consequences of the appraisal may influence a number of human resource management areas (Rousseau, 2001). One of the important processes that the appraisal may influence is the psychological contract (Stiles, Gratton, Truss, HopeHailey \& McGovern, 1997). Prior research has demonstrated that psychological contract breach is associated with various negative outcomes, such as a decrease in employees' perceived obligations to their employers, lowered citizenship behaviour and reduced commitment and satisfaction (Robinson, 1996). The aim of this study was to explore the influence of the performance appraisal on the psychological contract for the multinational organisation's remote subsidiary manager.

\section{Performance appraisal}

Performance appraisal is considered to be one of two key elements of performance management (Suutari \& Tahvanainen, 2002), with the other being the communication of organisation strategy through individual objective setting, development and compensation. Much of the research on performance appraisal has been performed within the United States (US) context (Dowling, Welch \& Schuler, 1999). Although there has been some research on international performance appraisal, little research has focused on the appraisal of the inpatriate manager. This dearth of research means that little is known about the effects of the appraisal on job satisfaction among employees in multinational organisations' subsidiaries (Taormina \& Goa, 2009). However, what little is known suggests that problems that have been identified at the national level are exaggerated when a organisation globalises its operations (Harvey, Speier \& Novicevic, 2001; Harvey, Novicevic \& Speier, 2002). Even for research focusing on the national situation, there is a lack of agreement among researchers with regard to the most effective criteria for assessing performance appraisal and the purpose of the procedure (Gratton, Hope-Hailey, Stiles \& Truss, 2001; Whitford \& Coetsee, 2006; Williams, 2002). It is, therefore, not surprising that multinational organisations frequently measure some attributes and behaviours of international employees that are inappropriate, and that international employees are despondent about their appraisals (Fenwick, 2004; Taormina \& Goa, 2009; Vance, 2006). 
At the Australian national level, the criteria for performance appraisal have received a great deal of attention from researchers and have been broadly divided into results and behaviours. Results are easily defined and can lead to superior productivity and business goals (Whitford \& Coetsee, 2006). However, this approach has a number of shortcomings (McGovern, 1999; Muchinsky, 2002). For instance, results-oriented measures may be deficient as performance criteria, because they typically tap only a small proportion of the job-performance requirements. Bae (2006) has argued that they create a results-at-any-cost mentality, which could generate dysfunctional behaviour and may be beyond the control of the manager. Behavioural criteria have been argued to give more control to the employee and allow for direct feedback. For example, the international research on appraisal criteria, although limited, suggests that behavioural criteria, such as employee attitude and conduct, provide a more helpful way of assessing the effectiveness of appraisal in the global context (Harvey, 1997; Milliman, Taylor \& Czaplewski, 2000).

The behavioural criterion of 'acceptability' of the performance appraisal is a fairly recent addition to the field and research literature on acceptability from the perspective of the employee is limited. An exception is a recent study conducted in China (Taormina \& Goa, 2009), which found performance-appraisal acceptability to be paramount, and that it related to the way the performance-appraisal process was executed. In the same way, ratee appraisal acceptability in an international context has been found to increase when the ratee has regular communication and a positive relationship with the rater (Milliman et al., 2002). From the perspective of the appraisee, acceptability is more likely to occur when he/she perceives the appraisal to be fair (Bradley \& Ashkanasy, 2001; Taylor, Masterton, Renard \& Tracey, 1998), and when the feedback he/she receives from the appraiser is timely and accurate (Cascio, 2000; Milliman et al., 2000; Sully De Luque \& Sommer, 2007; Williams, 2002). Moreover, where a subordinate and supervisor are geographically distant, regular feedback has been found to be particularly important (Cascio, 2000; Harzing \& Noordhaven, 2005; Milliman et al., 2002; Sully De Luque \& Sommer, 2007). Hedge and Teachout (2000) have claimed that acceptability may be the critical criterion for determining the success of an appraisal process.

In the international setting, a vital aspect of the acceptability of the performance-appraisal process to both the supervisor and the employee has been found to be attributed to the clarity of purpose of the appraisal (Lindholm, 1999; Maley \& Kramar, 2007; Milliman et al., 2002). Consequently, a multinational organisation's purpose for conducting appraisals needs to be transparent. In other words, not only should the subordinate's and supervisor's expectations be aligned, but both also need to be in congruence with the organisation's rationale for conducting the appraisal (Milliman et al., 2002; Shen, 2005; Whitford \& Coetsee, 2006). Furthermore, Milliman et al. (2002) argue that the purpose of appraisal, in addition to controlling individuals and maximising the organisation's financial performance, is to develop the employee, engender allegiance and allow subordinate expression in an environment of trust.

Along similar lines, Fenwick (2004) states that international appraisal has two purposes: evaluation and development of performance. She argues that, in the context of international performance management, appraisal should be the means by which compensation decisions are made and training and development needs are identified. However, training and development have been found to be infrequently linked to the purpose of appraisal (Williams, 2002). Murphy and Cleveland (1995) claim that, while over $85 \%$ of organisations use appraisals for administrative purposes, in particular salary decisions, appraisals are rarely used for training and development purposes.
Murphy and Cleveland (1995) also expressed a key concern that goals pursued by the rater and ratee are not necessarily the same as those pursued by the organisation. The above argument was also advanced by Milliman et al. (2002), who propose that expectations may be high in relation to what can be realistically achieved through performance appraisals, and that organisations need to devote more time and effort to the purpose of performance appraisal. Furthermore, they concluded that the purpose of appraisal has fallen short not only in the US, but in 10 other countries they sampled. Whitford and Coetsee (2006) examined performance appraisals in a large life insurance organisation in South Africa and also found that appraisal purpose was frequently unclear.

Performance-appraisal acceptability and the purpose of appraisal emerge from the literature to be both paramount and interdependent. Evidence suggests that, from an employee perspective, in order to be acceptable the appraisal needs to have a clear purpose, and the appraisal purpose has to be acceptable. The relationship between purpose and acceptability reinforces the need for appraisal to be embedded in a performancemanagement system rather than to stand alone as a human resource event. For example, if appraisal is part of a fully fledged performance-management system, it is more likely that the appraisal will be linked to the organisation's strategy and that both compensation and training and development needs will be achieved. Under these conditions the appraisal is more likely to be acceptable to the ratee.

\section{Construct theories}

Undoubtedly, performance appraisal has long been one of the most perplexing and troublesome topics in human resource management, which could be based on the fact that no-one likes to be evaluated. Construct theories have been used to attempt to understand the behaviours that occur during performance appraisals. For example, a psychological explanation for people's resistance to performance evaluation could be that a negative evaluation can represent a threat to one's self-efficacy. Consequently, it might be expected that these feelings might be reduced to some extent if the appraisal criteria were acceptable and the purpose clear to the person undergoing the appraisal. The threat to self-efficacy that may occur in a dysfunctional appraisal could have a flow-on effect on many psychological aspects of the employee-employer relationship. Cognitive Dissonance Theory (Festinger, 1957) is a theory on the basis of which aspects of performance appraisal may be interpreted. From the perspective of Cognitive Dissonance Theory, a negative evaluation from another person would be inconsistent with the individual's general upbeat perception of him-/herself as a capable person. Such conflicting cognitions would possibly affect the spirit of the individual's relationship with the organisation, in other words his/her psychological contract.

Organisational Justice (Colquitt, Kossek \& Raymond, 2001) is another theoretical construct on the basis of which performance appraisal may be viewed. A dysfunctional performance-appraisal system may affect the employee's perception of organisational justice. This construct may help to explain employees' attitudinal and behavioural reactions to both performance appraisal and organisational commitment (Masterson, Lewis, Goldman \& Taylor, 2000). Because the appraisal has implications for individual reward, employee perceptions of justice are especially significant. Erdogan (2002) claims that Organisational Justice has two subjective perceptions: procedural justice (the fairness of procedures) and distributive justice (the fairness of outcome). For example, when employees feel unfairly treated in their appraisal, they are likely to react negatively. Distributive justice is concerned with the perceived fairness of the outcomes or allocations received. In appraisal, to reach a perception of distributive justice, individuals compare their efforts with the rating they receive and the fairness of that rating (Erdogan, 2002). 
On the basis of the two construct theories above, an appraisal is unlikely to be perceived as acceptable unless those involved in the process perceive it as unbiased (i.e. from the perspective of Cognitive Dissonance Theory) and fair (i.e. from the perspective of Organisational Justice Theory). It is reasonable to expect that, if an employee believes that he/she is being treated unfairly by the organisation, this will in turn impact on his/her perception of his/her relationship with the organisation. Therefore, Cognitive Dissonance Theory and Organisational Justice Theory assist in understanding the relationship between the appraisal and the psychological contract.

\section{The psychological contract}

The psychological contract was originally defined by Argyris (1960) to draw attention to the subjective dimension of the employment relationship. Over the past 15 years this early framework has been developed significantly, primarily under the influence of Rousseau (1989; 1995; 1998; 2001), and has become a major analytical device for promoting and explaining sustained employee motivation and commitment. A number of commentators (Arnold, 1996; Robinson, 1996; Rousseau, 1989; Rousseau \& Tijoriwala, 1998) have referred to the psychological contract as 'an unwritten contract' and have identified two major types of contracts: transitional (e.g. pay and career progression in exchange for hard work) and relational or social exchange (e.g. job security in exchange for loyalty). Together, these expectations are described as the assumptions or expectations that both employers and employees have about their responsibility to one another that go beyond the formal employment contract' (Grimmer \& Oddy, 2007, p.158). Empirical evidence supports a positive relationship between perceived contract fulfilment and employees' commitment to the organisation (Coyle-Shapiro \& Conway, 2005; Robinson, 1996; Robinson \& Morrison, 1995) and a negative relationship association with the neglect of in-role job duties and turnover intentions (Turnley \& Feldman, 1999).

Fundamental to a successful psychological contract is an understanding of people's expectations from employment (Atkinson, Barrow \& Connors, 2003; Cullinae \& Dundon, 2006). In fact, Levinson, Price, Mundeen and Stolley (1962) suggested that the psychological contract is a series of mutual expectations. Schein (1978) claimed that these expectations cover not only the actual job at hand and basic objectives, but also a whole set of obligations, privileges and rights. He also contended that employee dissatisfaction and alienation comes from violations of the psychological contract, which may be dressed up as explicit issues, such as pay and working hours. Developing this further, Rousseau and Tijoriwala (1998) reconceptualised the psychological contract, stressing an emphasis on the individual employee's sense of obligations, rather than expectations, on the assumption that unmet obligations are more damaging than unmet expectations. They argued that the psychological contract is an individual employee's belief in mutual obligations between him-/herself and the employer.

\section{Commonalities of the psychological contract and performance appraisal}

The psychological contract and the performance appraisal have commonalities. First and foremost, they are both grounded in social exchanges and rely on the norm of reciprocity as the explanatory mechanism for their consequences on employee attitude and behaviours. For example, Milliman et al. (2002) assert that one of the purposes of performance appraisal is engendering allegiance and trust. Correspondingly, a major part of the rationale behind the need for a psychological contract is the need to generate commitment and satisfy employee expectations (Thompson, 2003), and the need to incorporate central work issues of trust and fairness (Guest, 2004; Robinson, 1996). The two frameworks also have similar complexities. For example, in a manner very similar to performance appraisal, research on the psychological contract has suggested that companies often give mixed messages about the terms of the psychological contract, and that these terms are poorly communicated by managers (Cullinae \& Dundon, 2006). Also, studies have shown that an emphasis on individual psychological contracts in an organisation can necessitate a heavy emphasis on individuals and weaken teamwork (Bacon, 2003). Additionally, the theoretical complexities in both frameworks have been argued, usually separately, to underpin their future usefulness. The exception here is a study by Stiles et al. 1997. They reviewed the management of performance in determining the psychological contract-making process in circumstances of change. They found that employees' deep concerns about accuracy and fairness of the performancemanagement process created scepticism and had a negative effect on the psychological contract. Nonetheless, the common ground shared by the two paradigms would suggest that the application of these two constructs could help achieve a similar set of outcomes, for example effective mutual commitment by the employer and the employee, and organisational citizenship behaviour that is aligned with the strategy of the organisation.

Performance appraisal has received intense attention from researchers over the past three decades. Research has progressed in traditional content areas (Tziner, Murphy \& Cleveland, 2005) and has also explored some new areas, such as contextual aspects (Levey \& Williams, 2004). Nonetheless, there still remain significant gaps in performance-management studies. Although the consequences of utilising performance appraisal in international contexts have received some attention (Dowling et al., 1999; Harvey, 1997; Shen, 2005), the inpatriate manager and his/her appraisal have been neglected. As a consequence, the aim of this study is to explore the extent, nature and limitations of performance appraisals, and the subsequent influence that these issues may have on the psychological contract of inpatriate managers. The next part of this article describes the research design used in the study. The third part of the article presents the results and focuses the discussion on the factors that influence the appraisal and its impact on the psychological contract. At the end of the article certain conclusions are drawn, and potential issues and opportunities are identified in the sphere of the inpatriate manager's appraisal and psychological contract. The implications for practitioners in multinational organisations are also discussed.

\section{Research approach}

\section{RESEARCH DESIGN}

The objectives of the study were achieved using a qualitative methodology, namely grounded theory. This approach involves identifying the relevant variables in data, rather than focusing on predetermined perspectives or variables. This approach is qualitative, subjective, humanistic and interpretist. It enables the researcher to capture both the behaviour of the participants in natural settings and the context that gave the behaviour meaning. This enables the theory to logically emerge from the study (Glaser \& Strauss, 1967). Using the grounded theory approach, the discovery and conceptualisation of the process under study are embedded in the empirical data. For example, this method involves both an inductive and deductive approach to theory construction and attempts to achieve one or more of the objectives of both qualitative and quantitative research given by Denzin and Lincoln (1994), namely (a) to initiate new theory, (b) to reformulate theory, (c) to refocus theory, or (d) to clarify existing theory. As stated above, grounded theory is a useful approach when relatively little is known about the topic, or few adequate theories exist to accurately explain or predict outcomes. This was clearly the case in this study.

\section{Research strategy}

The focus of the study was inpatriate managers currently employed by medium-sized Australian subsidiaries in a significant sector of the health care industry. This study focused on the major factors that influence the inpatriate manager's experience of performance appraisals. The grounded theory approach used in this study generated a significant 
amount of data on the appraisal experience of inpatriate managers. This approach also enabled the exploration of the factors that influenced this experience and the impact on the psychological contract. These findings were then interpreted from the perspective of their potential breach of the inpatriate's psychological contract.

\section{Research questions}

The specific research objectives were to explore two critical components of human resource management: the appraisal and the psychological contract. Before outlining the research questions, it is important to emphasise some important points about grounded theory. Because the framework of grounded theory evolves during the research itself, the initial research questions tend to be broader and less specific than with other research approaches (Strauss \& Corbin, 1990). The grounded theory approach is useful when little is known about a situation, and for this reason it is a valuable methodology for studying the inpatriate manager. The methodology generates theory from the data, instead of trying to fit the data to a hypothesis. Therefore, if it succeeds, an original contribution to the knowledge of performance appraisal is achieved. However, to the scholar unacquainted with grounded theory, the hypothesis may appear underdeveloped.

Considering these points, the following key research question was formulated:

- What are the main factors that influence the experience of the inpatriate manager's appraisal?

This research focused on the inpatriate manager, specifically addressing the following sub-questions:

- What are the causes of these factors?

- Dothesecauses breach theinpatriatemanager's psychological contract with the organisation?

\section{Research methods Research setting}

The majority of interviews took place during a quiet time in the participants' offices. For some this was early morning; for others it was at the end of the day. 17 interviews took place at the participants' work places, and one was conducted in an airport lounge. At the commencement of each interview a brief profile was taken of each participant, including sex, age group, education, number of years as inpatriate manager, time in current position, nationality and country of origin. The participants were employed by companies whose products are used in medical diagnostics, medical devices, life science and equipment industries. The range of products manufactured by these companies is diverse, extending from everyday items used in large quantities, such as bandages and syringes, to sophisticated and costly items of capital equipment, such as $\mathrm{X}$-ray, imaging and radiographic equipment, implants and fine measuring devices. Health care companies are among the top industry performers; in the US the market is worth US $\$ 1.6$ trillion, while in Europe it is worth US\$700 billion. In Australia, the industry has been estimated to be worth $\mathrm{A} \$ 5$ billion in local sales (CSI, 2008). The ageing population and increasing need for sophisticated diagnostic procedures and medicines guarantee industry longevity. This study specifically examined the nonpharmaceutical sector of the health care industry and excluded large pharmaceutical companies. Health care covers many subdisciplines and it was beyond the scope of this study to examine the whole health care market in Australia.

\section{Entrée and establishing researcher roles}

Key participants were initially contacted either by telephone (6) or e-mail (12). An appointment was made for the initial interview at a time and venue convenient to the participant. Participants were advised both verbally and in writing that participation was voluntary and that they could withdraw at any time. Permission to record the interviews was freely given by all participants. The initial interview with each participant lasted an average of 65 minutes (the longest was 120 minutes and the shortest was 45 minutes). The transcripts of a total of 20 hours of interviews formed the major data source for this study. Also, there were notes on second- and third-round interviews, notes on informal interviews, field notes, performance-appraisal documents and other literature sources that were incorporated during the study.

\section{Sampling}

The population consisted of a non-probability purposive voluntary sample of inpatriate managers in Sydney, Australia. 24 inpatriate managers from different health care multinational organisations were asked whether they would agree to be interviewed and 18 accepted. There were 17 males and 1 female and the age range varied from 35 years to 63 years, with a mean age of 48 years. Inpatriate managers from the US (6), United Kingdom (UK) (3), Denmark (2), France (1), Norway (1), Sweden (2), Switzerland (1) and Germany (2) were represented in the study. The participants were selected for the study based on certain criteria:

- They currently held a position as an inpatriate manager of a medium-sized Australian subsidiary of a health care multinational organisation (subsidiary turnover between A $\$ 10$ million and A $\$ 100$ million.)

- They reported directly overseas.

- They had held their position for more than two years.

- They had had at least two performance appraisals as inpatriate manager.

\section{Data-collection methods}

Data were collected from a variety of sources, including organisation documents, field notes, memos, appraisal documents and, most importantly, formal interviews with the 18 inpatriate managers. Interviewing as a method of data collection was selected because it was considered to provide the most suitable approach to study the participants in their own normal, everyday world, which is the premise of grounded theory (Glaser \& Strauss, 1967). The interview questions were semi-structured in order to give the interviews some direction, but at the same time permit enough flexibility, again in accordance with the guidelines of grounded theory. The researcher conducted all the interviews herself and the data were collected over a six-month period from July 2003 to January 2004. Participant observation commenced in 1999 and extended to December 2002 (during which time the researcher was working as an inpatriate manager). Documents and literature were examined during the whole period of the study.

As the study progressed, theoretical sampling (Glaser, 1978) was employed, with the researcher seeking participants and other data sources as directed by the initial findings of data analysis. Additional participants included a supervisor of inpatriate managers based in the UK, two international human resource managers, two industrial psychologists and two professional recruiters. The aim of this approach was to look for variation, and to seek data that shed more light on the developing themes, or emerging new properties of the categories or processes. This targeted interviewing approach (Silverman, 1989) enabled significant specific issues to be pursued, as well as verification of data about issues that appeared to be controversial, sensitive, or about which there appeared to be some misinformation. Seven key participants were interviewed twice and two were interviewed three times. Re-interviewing enabled the verification, clarification and elaboration of data obtained in the first interview, or the cross-checking of data acquired from other sources. Interviews ceased when saturation of the main theoretical category (or in grounded theory terms, core category) had occurred; that is, when no additional data were found from which new theoretical categories or properties of the categories could be developed. 


\section{Data-recording analysis}

The interviews were tape-recorded with the permission of the participants, and it was also emphasised that the identity of the participants would remain anonymous and that the participants could withdraw from the study at any time.

\section{Data analysis}

The recorded interviews were transcribed verbatim. The constant comparative method of qualitative analysis using NVIVO software was used as a means of coding the data. Collection, coding and analysis of data were a major operation. Data analysis, including coding and memoing, was conducted based on methods described by Glaser and Strauss (1967), Glaser (1978), Strauss (1987) and Strauss and Corbin (1990). Glaser selects an area for study and allows issues to emerge, whereas Strauss and Corbin are more specific and prefer to identify a phenomenon (Parker, 1994). This study used both methods. The writing of theoretical memos detailing the theoretical dimensions and implications of codes and the development of core categories and relationships formed the substance of the theoretical framework. Open coding involved the labelling of events, activities, functions, relationships, influences and outcomes. Subsequent axial coding required the recombining of closely related and overlapping codes into aggregate key concepts. Selective coding involved the selection of the central phenomenon from the key concepts and its designation as the core code, which was then related to the other key concepts directly and indirectly. This provided the derived grounded theory framework.

Once this was done, the analysis was directed towards identifying the core category. This was a process that formed the substance of the theoretical framework, which alternated between inductive and deductive thought. First, the researcher inductively determined meaningful groupings or potential categories, which were apparent from the data collected. Next, a deductive approach was used that allowed the researcher to turn away from the data and think rationally about the missing data. Theory was generated by systematically sorting and categorising the collected and partially analysed data by a process of constant comparative analysis. According to Glaser and Strauss (1967), the term 'comparative analysis' is used because every datum is compared with every other datum, rather than comparing totals of indices.

The data obtained in the interviews with the inpatriate managers was used to assess the effectiveness of the appraisals. The participants' appraisals that emerged from the data as being effective for the inpatriate managers were initially labelled 'exemplary'. Effectiveness of the appraisal became apparent in three ways: Firstly, the contribution of the appraisal to the inpatriate's own development; secondly, the effect of the appraisal on the inpatriate's motivation; and, thirdly, the inpatriate's perceptions of the appraisal's overall benefit to the organisation. Thereafter, the term 'exemplary' was used when the participants considered their appraisals to be effective.

\section{Strategies employed to ensure data quality \\ Data quality was ensured in several ways:}

- The application of triangulation was the primary means to ensure data quality, and boiled down to the use of various data-collection techniques, namely in-depth interviews with key participants, interviews with additional secondary but also pertinent participants, content analysis of various relevant documents and participant observation.

- The participants in this study were informed of the voluntary nature of their involvement and that they could withdraw from the study at any time during the research.

- Confidentiality of the participants was respected and protected. None of the participants were aware of the other participants who took part in the study.
- Written permission was given by each participant to record the interview, and they were informed that they could request the tape to be turned off at any time. Furthermore, all participants were advised that they could review the transcripts if requested.

- Purposive sampling was applied by selecting only employees who fitted set criteria, namely they had served two years as an inpatriate manager and had undergone at least two performance appraisals in their current role.

- Conscientious application of the constant comparative analysis method helped reduce any possible observer effects. In addition to the interviews, a diary was kept to record personal feelings and viewpoints during the research to heighten levels of awareness.

\section{RESULTS}

\section{Satisfaction with the performance appraisal}

Only three multinational organisations were found to conduct exemplary performance-appraisal systems. The most outstanding features to emerge from these multinationals were that their appraisals involved frequent face-to-face contact with the supervisor, appropriate and regular feedback and appraisal follow-up, and that they were directly related to a defined career path. According to the participants, their exemplary appraisals significantly contributed to their long-term retention in the organisation, which they believed gave their appraisals purpose. As a result, this group of participants thought that their appraisal met the criteria of acceptability.

\section{Limitations of the performance appraisal}

In contrast to the three instances of satisfaction, it was found in this study that, although performance appraisals were widely used, they were for the most part performed inadequately. More than $41 \%$ of the appraisals were conducted over the phone without any face-to-face contact, and less than one-third of the participants believed that they received any benefit from their appraisal. The results of the appraisals were used to make bonus decisions in almost $85 \%$ of the companies, but only $23 \%$ of the inpatriates' supervisors used the appraisal data to make training and development decisions. The findings showed that there were considerable limitations in the management of performance appraisals, namely inadequate face-to-face contact with the supervisor, lack of opportunity for feedback by the inpatriate manager, and limited (or total absence of) follow-up after the appraisal. Furthermore, this group of participants all reported that they did not have a definitive career path with their organisations and as a consequence their expectations for career advancement were not met. It became evident that they believed the appraisal should assist in their career development. The lack of career advancement was discovered to be a significant factor that contributed to the participants perceiving that their appraisal served no purpose. As a consequence, the appraisals failed to meet the criteria of acceptability.

\section{Face-to-face contact}

It was found that the majority of the inpatriate managers and their supervisors infrequently met face-to-face. One participant met his boss once every three months, but another had not had face-to-face contact with his boss for over two years. On average, the inpatriate managers and their supervisors met twice a year. Each inpatriate manager was also questioned as to where he/she met the supervisor and the quality of contact. Answers varied enormously. For example, inpatriate managers typically visited the head office once a year or, where a region existed, twice a year. Several participants spoke about doing many things and seeing numerous people when they visited the regional or head office, and there was often not much time spent with their supervisor. For example:

'When I go there I don't get much time with F. Well, the last time I hardly saw him. I run around like a headless chicken, with so many people to see.' 
It would be unlikely that the inpatriate manager and boss could strengthen their relationship with so little time for face-to-face contact. A major grievance from the participants was that, when their supervisors visited the subsidiary, their trips were too short, which exacerbated both lack of face-to-face contact and insufficient feedback. The participants whose appraisals were conducted over the phone, in all cases, did not think that this was appropriate. One participant expressed a typical view of the situation:

'For the last three years my appraisal has been over the phone. It's as though he doesn't have the courage to face me. It's really a joke. I find the whole process farcical.'

\section{Feedback}

Insufficient feedback was another frequent subject of discontent. To some extent, this is understandable considering the poor regularity of face-to-face contact. $78 \%$ of participants were dissatisfied with their feedback, for example:

'I get no time to air my grievances because it's just not possible with the kind of management that I get. There is no time for feedback.'

In some cases feedback was felt to be problematic because the setting of the appraisal was unsuitable, as in the case of an inpatriate manager whose only opportunity for feedback and follow-up was the performance appraisal itself, which was held in a noisy hotel restaurant:

Researcher:

'Were you given any opportunity for feedback?'

Participant:

'Well no, not really, er ... not at all, well, how can you do that when you have your appraisal in a busy restaurant in Singapore? Anyway, feedback wasn't on the agenda, so I really didn't push the issue.'

\section{Follow-up}

Follow-up was the third area of frequent dissatisfaction. All participants were asked about the follow-up subsequent to their appraisal. $90 \%$ of the participants stated that they did not receive any appraisal follow-up. For example:

'After he has finished the appraisal, well, that's it for another year. I can guarantee that we will never talk about what we discussed until the same time next year. It's like an annual ritual, a bit meaningless and it really doesn't fit with the real business.'

In sum, poor face-to-face contact, inadequate feedback, and almost non-existent appraisal follow-up were the most significant areas of discontent expressed by the participants and were identified by the researcher as being directly related to the key factors that influence inpatriate manager appraisals.

\section{Influences on performance appraisals}

The data revealed two core problems that represented major influences on the performance-appraisal process for inpatriate managers. Firstly, inpatriate managers' appraisals were found to be limited because of organisations' overwhelming short-term emphasis on sales and profit, which was termed the 'bottom line'. All the other phenomena were found to relate to this category. In other words, everything was found to be dependent upon organisations' obligations to secure sales and profit. All inpatriate manager participants in the study spoke repeatedly about the need to achieve financial results and quantitative aspects of their job, which included market shares and volumes of sales. They also talked about the external quantitative measurement or their organisations' obsession with the 'bottom line' to the detriment of all other measurements. The evidence was salient throughout the study: The participants were aware that financial performance was paramount.

Secondly, the inpatriate manager was disadvantaged by being solely dependent on the remote relationship with his/her supervisor, who rarely had any commitment to the inpatriate manager's appraisal because his/her primary concern was the sales and profits of the business. Most of the inpatriate managers in this study felt that the success of their appraisal interview depended on the nature and frequency of the interactions with their supervisors and the quality of the relationship. The lack of contact did not create trust or a sufficient relationship to enable an effective performance assessment. The short-term emphasis on the bottom line was the chief finding or, in grounded theory terms, the core category of this study, with the relationship with the supervisor being a secondary or near core finding.

\section{Core categories and limitations}

The three key limitations of performance appraisal found in this study, namely the limited face-to-face contact with the supervisor, the lack of feedback and absence of appraisal followup, were caused by either the core category, the emphasis on the bottom line, or the near core category, the manager's relationship with his/her supervisor. The core categories and the limitations of appraisal are, therefore, interrelated. Regular contact, preferably face-to-face, timely feedback and appraisal follow-up were regarded as necessary for an effective appraisal. Figure 1 displays the two main categories, one of which is the basic social process or core process, namely the bottom line (the largest circle). The other main category or near core category (medium-sized circle) is the relationship with supervisor, upon which the performance appraisal was contingent. The three small circles represent the limitations.

\section{Influences on the psychological contract}

Evidencesuggests that the threemultinational organisations that conducted exemplary appraisals had a positive psychological contract with their inpatriate managers. All participants from these organisations exhibited a strong social exchange construct towards their organisations. For example, they all perceived that they had a positive, clearly defined future career with their organisations and, consequently, they reported that they felt secure in their jobs. This sentiment was not expressed by the remaining participants, who did not have exemplary appraisals. In other words, the participants who had exemplary appraisals felt that their organisations understood their implicit raison d'êtres and, in turn, the participants reported that they understood the explicit expectations of their organisations. One participant described this in the following way:

'I think we're singing from the same hymn sheet.'

A second participant who had experienced exemplary appraisals reported:

'I [am of the opinion] that my expectations have been met by xyz and will continue to be met.'

It became evident in the study that the expectations of the participants who had undergone exemplary appraisals were met by their organisations. The expectations of the remaining participants, who had received non-exemplary appraisals, were not satisfied; that is, these inpatriate managers believed that the organisations were not meeting their expectations. Their prospects for career advancement and a definitive career path were ambiguous. In other words, the multinationals were not fulfilling their side of the psychological contract.

\section{DISCUSSION}

This study has revealed two core problems that represent major influences on the performance-appraisal process for inpatriate managers. First of all, the inpatriate's appraisal was found to be limited because of the organisation's overwhelming short-term emphasis on sales and profit (the bottom line). Subsequently, the inpatriate was disadvantaged by being solely dependent on the remote relationship with his/her supervisor, who rarely had any commitment to the inpatriate's appraisal because his/ her primary concern was the sales and profit of the business. 


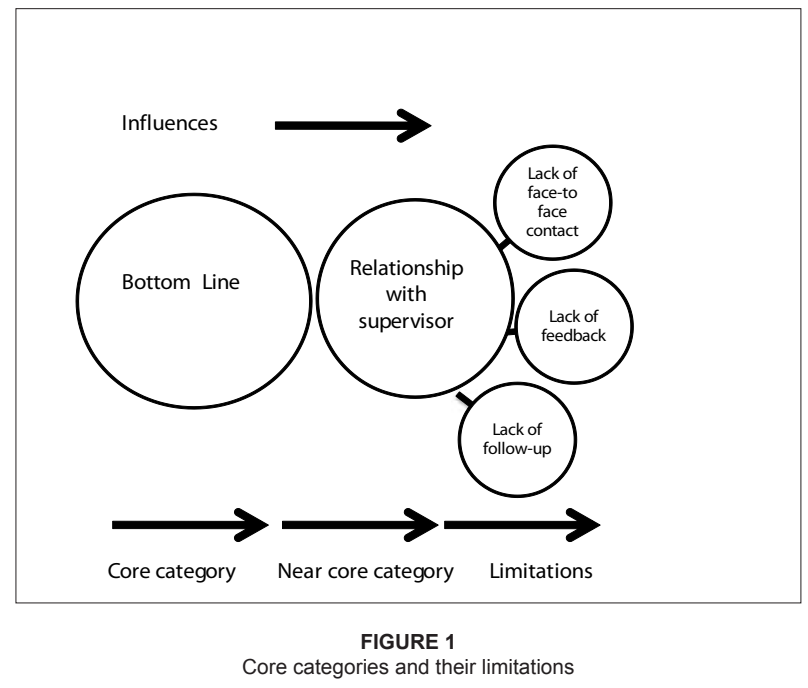

\section{Key factors influencing performance appraisal}

A limited range of criteria were used to assess the performance of the inpatriate managers. While there was compelling evidence of the use of results type criteria, there was less evidence of the application of behavioural criteria. In particular, there was little indication of the criteria of appraisal acceptability made apparent to the participants. Moreover, and in line with the findings of Bae (2006), this results-at-any-cost mentality was found to have a negative effect on the relationship between the supervisor and the inpatriate manager. The negative relationship between the inpatriate and his/her supervisor was further impaired by the lack of face-to-face contact, the limited feedback and the poor appraisal follow-up. The difficulties surrounding a lack of faceto-face contact for remote employees in distant subsidiaries have been previously documented (Harzing \& Noordhaven, 2005), and the theme of poor feedback between the rater and ratee has been well acknowledged (Harvey, 1997; Milliman et al., 2002; Taormina \& Gao, 2009). Conversely, the problem of poor appraisal follow-up does not appear to have been uncovered by previous researchers. Poor follow-up could be an indication that the appraisal is not part of a performance-management process. The underlying principle here is that if the appraisal is embedded in the overall context of a performance-management system, it will be linked to the organisation's strategy and will be more likely to be followed-up.

The purpose of the appraisal was also found to be ill-defined, and this created a great deal of angst for the participants. One the one hand, the supervisors explicitly viewed the purpose of the appraisal as a means to influence the financial results. On the other hand, the inpatriate managers implicitly considered that one of the key purposes of the appraisal was to support their career development. The purpose of the performance appraisal from the perspectives of the supervisor and the inpatriate manager are clearly not aligned. This misalignment of purposes means that the inpatriates' expectations are unmet, which in turn will have a detrimental effect on their psychological contract with the organisation. The finding, that the performance appraisal influences the psychological contract, is in agreement with that of Stiles et al. (1997). Building on the model suggested by Stiles $e t$ al. (1997), the frames of performance appraisal and psychological contract have been integrated to provide a more comprehensive understanding of the employee-employer relationship.

\section{Influences of performance appraisal on the psychological contract}

The influence of the performance appraisal on the psychological contract can be demonstrated in a cycle of inadequate feedback (see Figure 2).
The sequence starts with the inpatriate manager receiving poor feedback. This is followed by inadequate face-to-face contact between the inpatriate manager and his/her supervisor, and is further exacerbated by a limited performance-appraisal follow-up. This sequence of events results in a non-exemplary appraisal. The appraisal clearly does not meet the criteria of acceptability. Moreover, the supervisor and inpatriate manager's understanding of the purpose of the appraisal is not aligned; the supervisor thinks the purpose is to give support to the financial results, and the inpatriate manager thinks the purpose of the appraisal is to help him/her with career development. In reality, the inpatriate manager associates the appraisal with poor career opportunities and, as a result, his/her expectations are unmet. In other words, the inpatriate managers are of the opinion that the multinational organisations do not fulfil their obligations. This causes a loss of trust, motivation and commitment and has a detrimental effect on the psychological contract, which triggers another cycle of poor feedback. Evidence related to this cycle shows that not only does the multinational organisation neglect the explicit expectations expressed in the performance appraisal, it also neglects the implicit expectations of the psychological contract. As a consequence, the result of a poor performance appraisal is that two key management processes, the explicit performance appraisal and implicit psychological contract models, may be flawed.

The breach of the psychological contract could have more ominous and multifaceted consequences for the inpatriate manager and the multinational organisation. For example, employee dissatisfaction and alienation have been argued to stem from violations of the psychological contract. Schein (1978) found that violations of the contract may appear to be caused by obvious explicit issues, such as pay and working hours, but that in reality violations are caused by implicit concerns that the employee may not feel comfortable raising. According to this line of reasoning, the inpatriate managers could be claiming that their dissatisfaction with their performance appraisal is due to explicit issues such as inadequate feedback and a lack of face-toface contact and appraisal follow-up, when in fact the genuine source of their frustration could be an implicit cause, for example career limitation. According to Schein's (1978) argument, the participants may be apprehensive about their future place in the organisation, but feel less able to vocalise this issue. In other words, the participants' tangible and explicit complaints may be masking the implicit intangible aspects of the psychological contract breach.

Inpatriate managers' expectations of career advancement may be problematic for many multinational organisations. As a byproduct of globalisation and, more recently, the 2008 crisis in the world economy, job security has become rare. Rouseeau (1990) argued that employee prospects for long-lasting careers in a single organisation have been replaced by high contingent pay and training. The participants in this study may have achieved high contingent pay, but the majority did not believe they were receiving adequate training and career development. Employer breach of expectations in relation to job security or opportunities for development have been found to lead to feelings of injustice or betrayal among workers (Morrison \& Robinson, 1997). This betrayal has been found to lead to a central issue of lack of trust and fairness (Guest, 2004), which was clearly the case in this study with the majority of inpatriate managers. According to Erdogan (2002), it is probable that the betrayal affects the inpatriate's perception of both procedural and distributive justice.

\section{Improving the cycle of inadequate feedback}

In order to improve performance appraisals and, accordingly, strengthen psychological contracts, the cycle of inadequate feedback has to be broken. In accordance with the findings in the literature (Colquit et al., 2001; Erdogan, 2002; Masterton et al., 2000), the appraisal must be perceived by the inpatriate manager to have both procedural and distributive justice. Figure 3 illustrates how the cycle may be rectified. For example, if the 


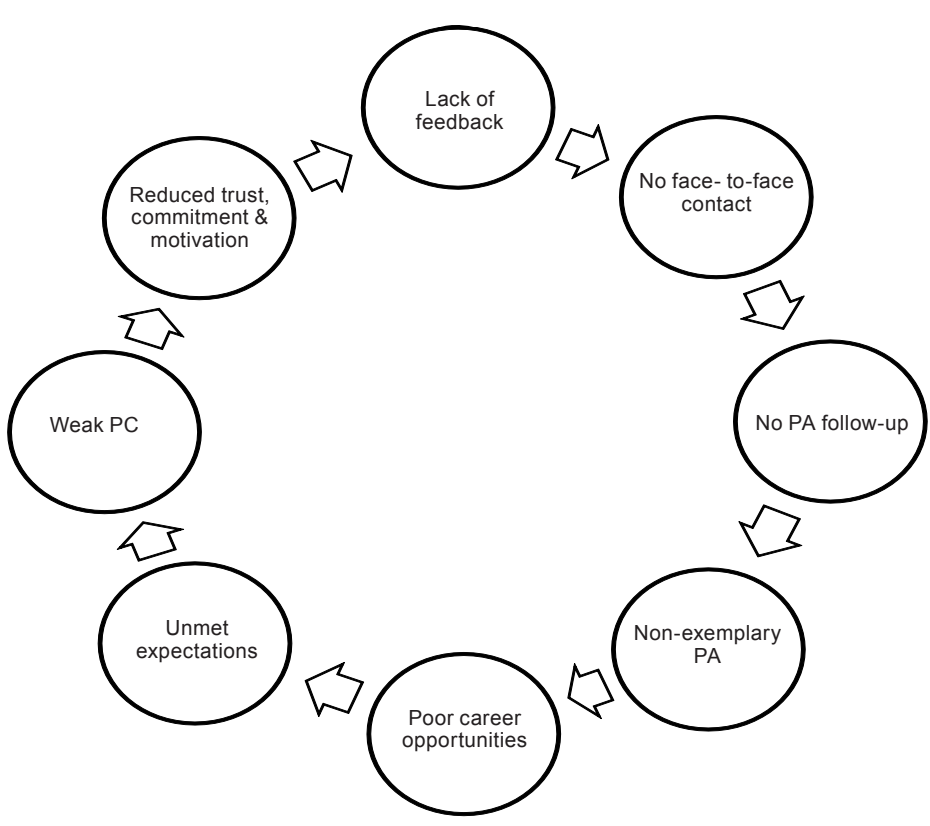

FIGURE 2

The cycle of inadequate employee feedback

inpatriate manager's performance appraisal includes timely feedback, adequate face-to-face contact and follow-up, his/ her appraisal will be exemplary. These are necessary but not sufficient criteria for a strong psychological contract. In an ideal situation, the inpatriate manager should have a clearly defined career path with the organisation. The appraisal will then more likely meet the important criteria of acceptability and may go some way to serving a well-defined purpose.

For many reasons, a definite career path, particularly in a small multinational organisation that has recently globalised, may not be possible. In this case, the organisation needs to be clear about the inpatriate manager's future. If the multinational organisation cannot offer a long-term career, the organisation can still develop the inpatriate manager by continuing to offer training and development. In other words, the organisation needs to consider providing the enabling resources, but does not necessarily need to take responsibility for the inpatriate manager's career Supportive and effective feedback can create conditions that encourage employees to find their own directions and guide their own activities (Cascio, 2000; Harvey et al., 2001). The key issue is that the inpatriate managers have clarity about their future

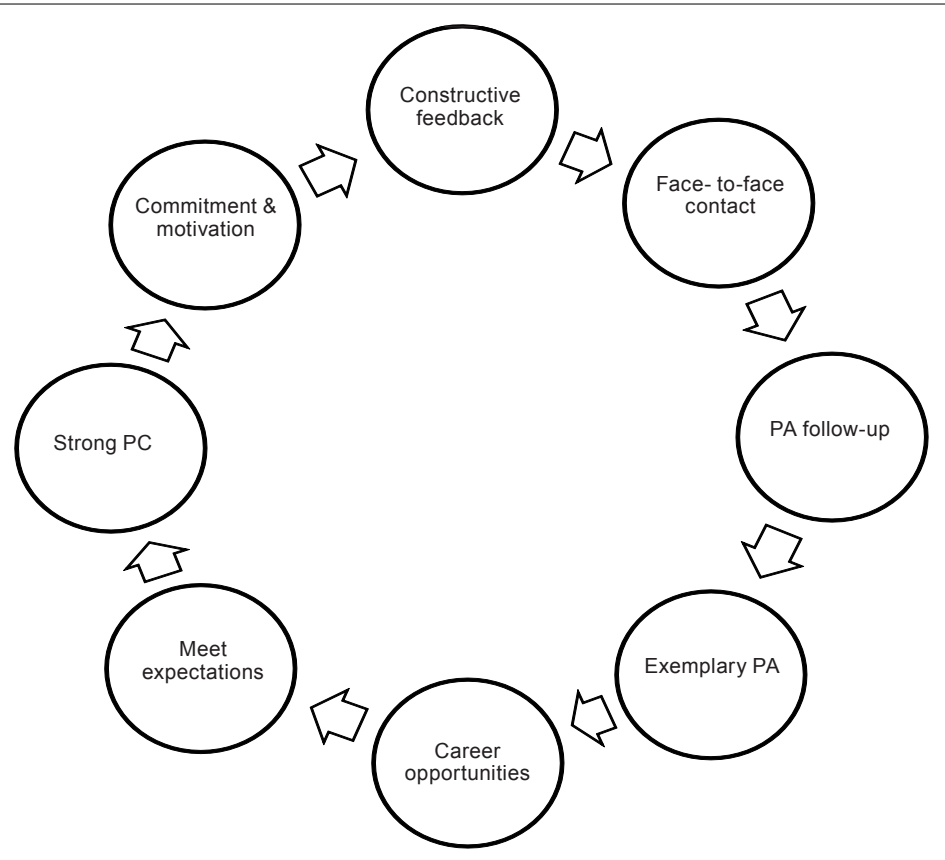


career directions and are not left with unrealistic expectations. If expectations are met, the theory of cognitive dissonance (Festinger, 1957) suggests that there would be no threat to the inpatriate manager's self-efficacy. When an exemplary appraisal is combined with clarity of career path, the appraisal has a purpose and meets the criteria of acceptability, and the inpatriate manager will have not only a feeling of positive self-efficacy, but also increased motivation and commitment. This will encourage positive feedback from the supervisor and there will more likely be a durable psychological contract. Therefore, the positive cycle is re-triggered (see Figure 3).

\section{Limitations}

This research was conducted in Sydney, Australia, in the health care business sector. This may lead to some limitations in the generalisability of results. 18 participants participated in the study and, while by grounded theory standards this is a sufficient number, it is not a large sample on which to make generalisations. Ideally, a comprehensive study should include all groups with whom the inpatriate manager interacts, but this was considered to be outside the scope of this particular study, as it was pioneering in the sense that it was aiming to apply a research approach that had not previously been used in this discipline.

\section{Conclusion}

This study has made a contribution to the field of international human resource management. It has identified that the literature has almost ignored the inpatriate manager and his/her performance management, despite the fact that this person's importance to the multinational organisation is increasingly growing. In addition, the research has established that there are several relevant constraints on the international performance-appraisal process for the inpatriate manager, and that, if performed inadequately, the appraisal is not only unacceptable to the inpatriate manager, but may also have a profoundly negative effect on the psychological contract of the inpatriate manager. The outcome could potentially rob the organisation of a valuable intangible asset, namely a fleet of motivated international executives. Furthermore, the study has recommended that, if a multinational organisation with a poor appraisal process and subsequent unsatisfactory psychological contract attempts to make some fundamental improvements to the performance appraisal of its inpatriate managers, it will not only be managing the competency of this important manager, but will engender commitment and loyalty.

These improvements, as suggested earlier, may be as straightforward as strengthening the feedback cycle and ensuring the inpatriate manager continues to develop his/her skills and improve his/her competencies. Importantly, it is vital that the inpatriate manager's expectations are congruent with those of the multinational organisation. In other words, his/her expectations need to be managed, and this can only be achieved if there is ample communication and opportunity for feedback between the supervisor and the inpatriate manager. Performance appraisals are fraught with difficulties at the national level, and yet are acknowledged as being important to an organisation's success. At the international level, distance and culture compound the problems and, more importantly, negligence in this area can have a devastating effect on the organisation's globalisation success. The multinational organisation may not be able to offer inpatriate managers life-long careers, but they can continue to develop them and manage their expectations. In the words of Jack Welch (the former CEO of General Electric), 'You can give lifetime employability by training people, by making them adaptable, making them mobile to go other places to do other things. But you can't guarantee lifetime employment' (Welch, 2001). Along these lines, the multinational organisation needs to be transparent with its inpatriate managers and manage their expectations. Notwithstanding, the fundamental improvements to the feedback cycle outlined above will assist organisations in not only improving the performance of inpatriate managers, but also assist in the critical role of developing their global talent pool, thereby giving the multinational organisation a distinct global advantage.

\section{Future research}

This study indicates that the experience of the performanceappraisal process in the international context and its relationship to the psychological contract could be illuminated by research in a number of areas. These include the influence of components of strategic human resource management systems, such as structure, incentives and communication processes. Studies in the virtual workplace on how appraisals are conducted and how the psychological contract is enacted could further illuminate some of the difficulties associated with the lack of face-to face contact between supervisors and employees, and the supervisory skills required in this environment.

\section{REFERENCES}

Argyris, C. (1960). Understanding organisational behaviour. Homewood: Dorsey.

Arnold, J. (1996). The psychological contract: A concept in need of closer scrutiny? European Journal of Work and Organisational Psychology, 5, 511-520.

Atkinson, P., Barrow, C., \& Connors, L. (2003). Models of police probationer career progression and the psychological contract. HRM Development International, 6, 43-57.

Bacon, N. (2003). HRM and industrial relations. In P. Acker \& A. Wilkinson (Eds.), Understanding work and employment: Industrial relations in transition. Oxford: Oxford University Press.

Bae, E.K. (2006, February). Major elements and issues in performance management systems: A literature review. Paper presented at the Academy of Human Resource Development International Conference (AHRD), Columbus.

Bradley, L., \& Ashkanasy, N. (2001). Performance appraisal interview: Can they be objective and are they useful anyway? Asian Pacific Journal of Human Resources, 39(2), 83-97.

Cascio, W.F. (2000). Managing a virtual work place. Academy of Management Executive, 12(3), 81-91.

Colquitt, J.A., Kossek, E.E., \& Raymond, A. (2001). Care giving decisions, well-beings, and performance: The effects of place and provider as a function of dependent type and work-family climates. The Academy of Management Journal, 44(1), 29-44

Coyle-Shapiro, J., \& Conway, N. (2005). Exchange relationships: An examination of psychological contracts and perceived organizational support. Journal of Applied Psychology, 90(94), 774-781.

CSI (2008). Diagnostics, medical devices and scientific products and equipment. Sydney: CSI.

Cullinae, N., \& Dundon, (2006).The psychological contract: A critical review. International Journal of Management Reviews, 8(2), 113-119.

Denzin, N.K., \& Lincoln, Y.S. (1994). Handbook of qualitative research. Thousand Oaks: Sage.

Dowling, P., Welch, D., \& Schuler, R. (1999). International dimensions of human resources. Cincinnati: South Western College Publishing.

Erdogan, B. (2002). Antecedents and consequences of justice perceptions in performance appraisals. Human Resource Management Review, 12, 555-578.

Fenwick, M. (2004). International assignments and expatriation. Asian Pacific Journal of Human Resources, 42(3), 365-377.

Festinger, L. (1957). A theory of cognitive dissonance. Stanford: Stanford University Press.

Glaser, B. 1978. Theoretical sensitivity. Mill Valley: Sociology Press.

Glaser, B., \& Strauss, A. (1967). The discovery of grounded theory: Strategies for qualitative research. New York: Aldine Publishing. 
Gratton, L. (2000). Living strategy: Putting people at the heart of corporate purpose. London: Prentice-Hall.

Gratton, L., Hope-Hailey, V., Stiles, P., \& Truss, C. (2001) Emerging themes in strategic human resource management. Oxford: Oxford University Press.

Grimmer, M., \& Oddy, M. (2007).Violation of the psychological contract: The mediating effect of relational versus transactional beliefs. Australian Journal of Management, 32(1), 153-175.

Guest, D. (2004). The psychology of the employment relationship: An analysis based on the psychological contract. Applied Psychology, 53, 541-555.

Harvey, M. (1997). Focusing on international performance appraisal process. Human Resource Development Quarterly, $8(1), 41-62$

Harvey, M., Novicevic, M., \& Speier. (2002). The evolution of SHRM systems and their application in a foreign subsidiary context. Asian Pacific Journal of Human Resources, 40(3), 284300.

Harvey, M., Speier, C., \& Novicevic, M. (2001). A theory-based framework for strategic global human resource staffing policies and practices. Human Resource Management, 12(6), 898-915.

Harzing, A.W., \& Noordhaven, N. (2005). Geographical distance and the role of management of the subsidiaries: The case of subsidiaries down under. Asian Pacific Journal of Management, 23, 167-185.

Hedge, J.W., \& Teachout, M.S (2000). Exploring the concepts of acceptability as a criterion for evaluating performance measures. Group and Organisation Management, 25(1), 22-44.

Levey, P., \& Williams, J. (2004). The social context of performance appraisal: A review and framework for the future. Journal of International Management, 30(6), 881-905.

Levinson, H., Price, C., Mundeen, K., \& Stolley, C. (1962). Men, management and mental health. Cambridge: Harvard University Press.

Lindholm, N. (1999). National culture and performance management in MNC. International Studies of Management and Organisations, 29(4), 45-66.

Maley, J., \& Kramar, R. (2007). International performance appraisal: Policies, practices and processes in Australian subsidiaries of healthcare MNCs. Research \& Practice in Human Resource Management, 15(2), 21-41.

Masterson, S., Lewis, K., Goldman, B., \& Taylor, M. (2000). Integrating justice and social exchange: The differing effects of fair procedures and treatment on work relationships. Academy of Management Journal, 43, 738-748.

McGovern, P. (1999). HRM policies and management practices. In L. Govern, V. Hope-Hailey, P. Stiles \& C. Truss (Eds.) Strategic human resource management. Oxford: Oxford University Press.

Milliman, J., Nason, S., Zhu, C., \& De Cieri, H. (2002). An exploratory assessment of the purpose of performance appraisal in North and Central America and the Pacific Rim. Asia Pacific Journal of Human Resources, 40(1), 87-107.

Milliman, J., Taylor, S., \& Czaplewski, A. (2000). Performance feedback in MNC: Opportunities for organizational learning. Human Resource Planning, 25(3), 29-44.

Morrison, E., \& Robinson, S. (1997). When employees feel betrayed: A model of how psychological contract violation develops. Academy of Management Review, 22, 226-256.

Muchinsky, P.M. (2002). Psychology applied to work. (6th edn). Belmont: Wadsworth.

Murphy, K., \& Cleveland, J. (1995). Understanding performance appraisal. New York: Sage.

Parker, L. (1994). Reactive planning in Christian bureaucracy: An examination of the Uniting Church of Australia, Synod of Victoria. Adelaide: University of Adelaide.

Robinson, S. (1996). Trust and breach of the psychological contract. Administrative Science Quarterly, 41, 574-599.

Robinson S., \& Morrison E. (1995). Psychological contracts and the OCB: The effect of unfulfilled obligations on civic virtue. Journal of Organisational Behaviour, 16, 289-298.
Rousseau, D. (1989). Psychological and implied contracts in organizations. Employee Responsibilities and Rights Journal, 2, $121-139$.

Rousseau, D. (1990). New hire perceptions of their own and employer's obligations: A study of psychological contracts. Journal of Organisational Behaviour, 11, 389-400.

Rousseau, D. (1995). Psychological contracts in organisations: Understanding the written and unwritten agreements. London: Sage.

Rousseau, D. (1998). The problems of the psychological contracts considered. Journal of Organisational Behaviour, 19, 665-672.

Rousseau, D. (2001). Schema, promise and mutuality: The building blocks of the psychological contract. Journal of Occupational and Organisational Psychology, 74, 511-542.

Rousseau, D., \& Tijoriwala, S. (1998). Assessing the psychological contracts: Issues, alternatives and measures. Journal of Organisational Behaviour, 19, 679-696.

Schein, E. (1978). Career dynamics: Matching individual and organisational needs. Reading: Addison-Wesley.

Shen, J. (2005). Effective international performance appraisals: Easily said, hard to do. Compensation and Benefits Review, 27, 70-80.

Silverman, D. (1989). Six rules of qualitative research: A postromantic argument. Symbolic Interaction, 12(2), 215-230.

Stiles, P., Gratton, L., Truss, C., Hope-Hailey, V., \& McGovern, P. (1997). Performance management and the psychological contract. Human Resources Management, 7(1), 57-66.

Strauss, A. (1987). Qualitative analysis for social scientists. New York: Cambridge University Press.

Strauss, A., \& Corbin, J. (1990). Basics of qualitative research: Grounded theory procedures and technique. Newbury Park: Sage.

Sully De Luque, M., \& Sommer, S. (2007). The impact of culture on feedback seeking behaviour: An integrated model and propositions. Academy of Management Review, 25(4), 829-849.

Suutari, V., \& Tahvanainen, M. (2002). The antecedents of performance management among Finnish expatriates. The International Journal of Human Resource Management, 13(1), $1-21$.

Taormina, R., \& Goa, J. (2009). Identifying acceptable performance criteria: An international perspective. Asia Pacific Journal of Human Resources, 47(1), 102-124.

Taylor, S., Masterton, S., Renard, M., \& Tracey, K. (1998). Manager's reactions to procedurally just management systems. Academy of Management Journal, 41(5), 568-579.

Thompson, P. (2003). Disconnected capitalism; or why employees can't keep their side of the bargain. Work, Employment and Society, 17, 359-378.

Turnley, W., \& Feldman, D. (1999). The impact of psychological contract violations on exit, loyalty and neglect. Human Relations, 52, 895-922.

Tziner, A., Murphy, K. \& Cleveland, J. (2005). Does conscientiousness moderate the relationship between attitudes and beliefs regarding performance appraisal and rating behavior? International Journal of Selection and Assessment, 10, 218-224.

Vance, C. (2006). Strategic upstream and downstream considerationsforeffectiveglobalperformancemanagement. International Journal of Cross-Cultural Management, 6(1), 3756.

Welch, J. (2001). Class day interview: Jack Welch to HBS Grads: “Don't be a jerk". Harvard Business School Working Knowledge. School Archives, 6, 11 .

Whitford, C. M., \& Coetsee, W.J. (2006). A model of the underlying philosophy and criteria for effective implementation of performance management. South African Journal of Human Resource Management, 1, 63-73.

Williams, R.S. (2002). Managing employee performance: Design and implementation in organisations. London: Thompson Learning. 